ESTUDOS REEP

\title{
A expansão da educação superior no Brasil: um estudo do caso Cesnors
}

Jorge Paiva da Silva

Maiane Liana Hatschbach Ourique

\section{Resumo}

Discute acerca do programa de expansão universitária implementada no Governo Lula (2003-2010) na tentativa de qualificar o debate sobre um acesso sustentável à educação superior. Para isso, empreende-se uma abordagem hermenêutica e crítica sobre os processos de transformação e expansão das universidades brasileiras, centrando o foco, de modo especial, na criação do Centro de Educação Superior Norte (Cesnors), ligado à Universidade Federal de Santa Maria (UFSM), Rio Grande do Sul. O fortalecimento de laços entre a comunidade e a universidade é, pois, o que segue às ações de democratização do acesso, no sentido de enraizar a qualidade da educação superior nos processos político-culturais da sociedade mais ampla.

Palavras-chave: universidade; expansão; acesso; qualidade. 


\section{Abstract \\ Expansion of college education in Brazil: a study of the Cesnors case}

This article discusses the university expansion program implemented during Lula's Administration (2003-2010) with the intent to qualify the debate on sustainable access to higher education. In order to achieve this, it is used an critical and hermeneutic approach on the processes of transformation and expansion of brazilian universities, focusing, specially, in the creation of the Centro de Educação Superior Norte (Cesnors), connected to the Universidade Federal de Santa Maria (UFSM). Therefore, the central argument to democratize access is the strengthening of ties between community and university in order to anchor the quality of higher education in the political-cultural processes of a wider society.

Keywords: university; expansion; access; quality.

\section{Considerações iniciais}

Para além de instrumento político e ideológico de abertura a novos mercados, a educação superior é um caminho para o desenvolvimento social com justiça e bem-estar. Ela incorpora a missão notável de produzir e difundir ciência, arte, tecnologia e cultura, materializando, assim, a "ideia de universidade" pensada por Humboldt há dois séculos. Esta ideia agregadora de diferentes elementos sociais, que carrega o próprio espírito da formação humana (Bildung), remete "para uma instância universal anterior ao pluralismo das formas de vida sociais. A ideia da universidade remete para os princípios culturais segundo os quais se constituem todas as configurações do espírito objectivo" (Habermas, 1993, p. 112).

Sabemos que, com a alta diferenciação dos sistemas organizacionais, as universidades, conforme lembra Habermas, já não encarnam ideias, mas buscam cada vez mais sustentarem-se na acolhida das demandas sociais. Deste modo, nosso estudo empenha-se em construir uma discussão mais aprofundada sobre as propostas de expansão universitária, especialmente aquelas implementadas no Governo Lula (2003-2010), visando compreender o significado que a universidade adquire no contemporâneo, bem como suas possibilidades de contribuir na formação do sujeito e da sociedade. Neste sentido, trazemos ao debate o contexto do Centro de Educação Superior Norte (Cesnors), cuja criação está inserida neste programa expansionista, para refletirmos os caminhos e percalços de um acesso sustentável à educação superior. 
Neste contexto de transformação e expansão das instituições universitárias, perguntamos: Em que sentido a ideia de universidade ainda pode contribuir para uma crítica hermenêutica sobre sua reforma? E qual racionalidade permeia a expansão da universidade brasileira deste início de século?

No debate sobre os processos de reforma e expansão da universidade, o modelo do idealismo alemão atualiza-se agora como critério para compreendermos a construção das identificações na/ com a instituição universitária em uma sociedade plural. Em outras palavras, se a ideologia dos mandarins alemães proporcionou à universidade uma forte consciência de si enquanto corpo, pode, por hipótese, também contribuir nos processos de fortalecimento de laços entre as comunidades e as unidades descentralizadas criadas em diferentes locais do Brasil, por exemplo, através de mecanismos comunicativos e/ou culturais característicos.

Por um lado, as estruturas institucionais da universidade foram formadas por um espírito objetivo que balizou a constituição da diversidade de corporações profissionais, no sentido de compreender cientificamente a pluralidade das manifestações naturais e sociais; por outro, sua consciência corporativa advém justamente da forma como organiza os processos de aprendizagem científicos e os insere nos modos de vida. Esta dialética imanente entre o campo científico e o campo social que configura a universidade é o ponto de partida para qualquer processo de avaliação e/ou transformação da educação superior, seja sob o critério da sustentabilidade, seja sob o da responsabilidade ou da pertinência social.

Para não afunilarmos o debate em uma perspectiva maniqueísta ou objetivista acerca dos resultados até agora alcançados, buscamos, num primeiro momento, compreender o sentido que a instituição universitária adquiriu na modernidade, para, então, hermeneuticamente, situá-la no atual contexto político-cultural. Neste segundo momento, focamos a discussão sobre algumas dificuldades e precariedades da proposta expansionista da universidade para concretizar o direito à educação como direito social. Tendo a democratização do acesso à universidade como um dos eixos de sua reforma, o número de vagas nas instituições públicas e privadas do País cresceu expressivamente, restando ainda para o debate público a discussão sobre a qualidade da educação superior. Por fim, no terceiro momento, apresentamos aspectos relevantes da realidade do programa expansionista por meio de um estudo do caso Cesnors, cujo papel estratégico que ocupa possibilita uma avaliação mais apurada de seus impactos no desenvolvimento econômico e cultural da Região Norte do Estado do Rio Grande do Sul. As expectativas sociais constituídas com a criação deste centro proporcionaram processos de identificação com a instituição de forma a refletir sobre as relações possíveis entre a ideia de universidade e seus impactos na dinâmica social. 


\section{A ideia de universidade}

Sabemos que a universidade brasileira estruturou-se a partir dos modelos napoleônico (monopólio estatal, laicização, divisão em faculdades compartimentadas, importância atribuída à colação de grau e ao diploma como requisito para o exercício da profissão) e alemão (centralidade no poder intelectual e na autonomia da ciência), recebendo a partir da década de 1968 também a influência do modelo americano, agregando às ações de ensino e pesquisa a utilidade da produção universitária para o mercado. A partir daí, o forte interesse na expansão da educação superior mediante a ampliação do número de vagas em universidades públicas e a proliferação de instituições privadas contribuiu para a sua massificação. Apesar da pressão da dimensão econômica pela racionalização do sistema universitário, a discussão acerca da importância da formação humana (Bildung) no interior das universidades permanece viva e justificável, uma vez que o cidadão socialmente desejável articula o aspecto epistêmico (da ciência, da profissão) ao humano (dos valores éticos e culturais) para a compreensão do mundo e das experiências vividas. Este caráter filosófico da universidade remonta a Wilhelm Von Humboldt, que fundou em Berlim uma instituição - hoje com seu nome - em 1810. Para se ter uma ideia de sua forte influência sobre outras universidades europeias e ocidentais, por lá passaram, entre outros, pensadores como Johann Gottlieb Fichte, Friedrich Schleiermacher, Georg Wilhelm Friedrich Hegel, Arthur Schopenhauer, Friedrich Schelling, Albert Einstein, Karl Marx e Friedrich Engels. Para Humboldt, todo o investimento no interesse moral, político e cultural da ciência reverte em contribuições sociais, bem como em formação individual. Como exigência importante para este desenvolvimento está a ideia da autonomia da universidade na busca do conhecimento e na condução dos processos que subsidiam a ampliação deste, cabendo às forças sociais, especialmente ao Estado, o provimento dos meios, da estrutura.

Cabe salientar que Humboldt tinha uma concepção bastante aberta da ciência, em que os resultados da pesquisa não são fixados de antemão e os caminhos do conhecimento são tomados conforme as possibilidades que se apresentam. Por sua parte, a individualidade do cientista não se refere a uma ação solipsista, mas pressupõe um nexo atuante (tätiger Zusammenhang), uma inserção na coletividade, uma experiência compreensiva na cultura - daí a importância da autonomia tanto da universidade quanto do cientista diante do conhecimento que está sendo produzido. Além disso,

Aos olhos de Humboldt, é um fato histórico que as universidades que se retraem em si mesmas podem, por um lado, esbaldar-se em tradições, mas perdem toda e qualquer significância para o presente e o futuro. Precisamente esta é a realidade das universidades alemãs na transição do séc. 18 para o séc. 19. Mas os exemplos das universidades de Göttingen e Jena mostraram que o intercâmbio com academias, os projetos práticos, o desafio do contato com poetas e tradutores, bem como a ligação com outras línguas e culturas, podem liberar impulsos 
científicos de longo alcance. Por isso está provado para Humboldt que a universidade chega a uma vitalidade efetiva somente na relação com as instituições circundantes. Assim, ela deve conseguir atuar no seu entorno e empenhar-se ao máximo em transcender as suas fronteiras. Ela deve estimular, absorver e fazer tudo o que fomente o intercâmbio de indivíduos extraordinários, justamente também além das barreiras convencionais. Uma universidade necessita - se possível bem no centro político do país - de uma posição excêntrica, a fim de assegurar para si a mobilidade da qual carece para ser intelectualmente produtiva. (Gerhardt, 2002, p. 22-23 - grifos do autor).

No modelo humboldtiano de universidade, a construção de conhecimento está intimamente relacionada com a produção cultural da comunidade em que se localiza, uma vez que o sentido expressivo da ciência se dá em função das experiências significativas dos cientistas - alunos, professores -, e os efeitos sociais desse conhecimento tocam, em última instância, os processos formativos de todos ao entorno. Como lembra Gerhardt (2002, p. 31), para Humboldt, a ciência teria por princípio uma organização social do espírito humano.

No entanto, esta idealização da universidade, marcada por um forte caráter inverossímil e incorporando em si todas as possibilidades de formação do homem, desviou-se para a efetivação de um modelo elitista e isolado que acreditou na institucionalização da ciência como forma de garantir a unidade entre ensino e pesquisa, entre ciência e esclarecimento crítico (Alfklärung), além da unidade da própria ciência em suas diferentes áreas. Ou seja, esta aglutinação de campos "sobrecarregou a autonomia da ciência com a expectativa de que a universidade pudesse, intramuros e como que numa espécie de microcosmos, antecipar uma sociedade de homens livres e iguais" (Habermas, 1993, p. 118). Atualmente, não apenas o modelo de universidade se multifacetou, mas o próprio estatuto da ciência se modificou:

A ciência antiga definia-se como teoria, isto é, para usarmos a expressão de Aristóteles, estudada aquela situação que independe de toda ação e intervenção humanas. A ciência moderna, ao contrário, afirmou que a teoria tinha como finalidade abrir o caminho para que os humanos se tornassem senhores da realidade natural e social. Todavia, a ciência moderna ainda acreditava que a realidade existia por si mesma, separada do sujeito do conhecimento e que este apenas podia descrevê-la por meio de leis e agir sobre ela por meio das técnicas. A ciência contemporânea, porém, acredita que não contempla nem descreve realidades, mas as constrói intelectual e experimentalmente nos laboratórios. Esta visão pós-moderna da ciência como engenharia e não como conhecimento, desprezando a opacidade do real e as difíceis condições para instituir as relações entre o subjetivo e o objetivo, leva à ilusão de que os humanos realizariam, hoje, o sonho dos magos da Renascença, isto é, serem deuses porque capazes de criar a própria realidade e, agora, a própria vida. (Chauí, 2001, p. 23-24).

Se por um lado, de modo geral, a ciência tem adotado uma postura autossuficiente, retroalimentando-se de suas próprias descobertas, por outro, tem aberto espaço para críticas sobre sua autoridade na 
organização da vida cotidiana. Assim, vivemos uma outra relação com a produção do conhecimento, cujas implicações sociais - de cunho ético e estético - precisam ficar mais explícitas, de modo a não ratificar os rótulos atribuídos à universidade, como "improdutiva", "rebelde", "alienada", entre outros. Contudo, esta exigência pela efetividade da educação superior não necessariamente a libera de uma compreensão secular de universidade, especialmente porque não estamos nos referindo ao sentido econômico, pura e simplesmente, que a universidade assumiu a partir de sua reforma nos anos de 1960, mas de seu papel estratégico na formação de uma sociedade voltada para os valores humanos e culturais mais caros. Por isso, na tentativa de dissolver a noção quase hegemônica da universidade operacional, administrada para a obtenção de resultados, Marilena Chauí, em entrevista ao programa Roda Viva da TV Cultura, lembra o importante papel que a filosofia e as ciências sociais exercem no interior das universidades:

Então, eu diria que a filosofia tem um papel dentro da política universitária, que é de lembrar, primeiro: a universidade que se propõe hoje não precisa ser assim e não deve ser assim, e que há alternativas. A filosofia pode repor a ideia de formação, no sentido amplo da formação cultural, e ela pode recolocar o sentido profundo da noção de pesquisa. Ao invés da pesquisa ser entendida como achar uma resposta pontual a um problema pontual, é repor a ideia da pesquisa como uma investigação e uma interrogação que abrange toda uma experiência contemporânea. (Chauí, 1999).

Este sentido cultural da pesquisa e do conhecimento, caro ao modelo humboldtiano de universidade, amplia, portanto, a compreensão da educação superior para além da lógica de mercado - da perspectiva econômica do saber - e rompe com os laços criados entre pesquisa e produtividade. Assim, a produção na universidade não está ligada aos resultados esperados pelo mercado nem pode ser mensurada tendo este como indicador. Tanto o olhar sobre a produção universitária quanto sua função de formação técnico-profissional do cidadão carregam em sua imanência a ideia da compreensão do "espírito do tempo" vivido, ou seja, a localização do sujeito nas discussões contemporâneas acerca do desenvolvimento sustentável, do convívio na/com a diferença, da transculturalidade, da tolerância, da paz, entre outras temáticas urgentes em nossa sociedade.

Enfim, se a relação entre universidade e sociedade tem assumido matizes mais interativos, exigindo uma reforma no pensamento e na postura de ambas, a "pertinência" e o "sentido social" da universidade se referem à perspectiva interpretativa e crítica que a educação superior deve manter em todas as suas ações e discussões:

Noutras palavras, responsabilidade ou pertinência social implicam sempre um posicionamento crítico com relação à realidade na perspectiva dos ideais humanitários de justiça social, liberdade, paz e desenvolvimento sustentado com tudo o que isso representa em termos de organização social, de desenvolvimento científico-tecnológico, de acesso aos bens culturais e materiais, de respeito e desenvolvimento cultural para todos os cidadãos. (Goergen, 2008, p. 811). 
Tendo em vista o alerta de Goergen de que discursos altruístas ou pragmaticamente afunilados não bastam para contribuir efetivamente no tratamento das problemáticas das instituições de educação superior, vamos abordar, no próximo item, as transformações por que passam as universidades na atualidade e as possibilidades apontadas até então.

\title{
Reforma, expansão e renovação da universidade
}

No cenário contemporâneo, especialmente a partir dos anos de 1970 com o acirramento da crise do capitalismo, o projeto neoliberal assume uma condição vigorosa como processo que repercute nas universidades através da tentativa constante de regular a educação superior pelo mercado globalizado, visto que seus diversos dispositivos ideológicos influenciam o processo decisório das políticas públicas:

\begin{abstract}
As universidades públicas, no contexto do neoliberalismo, são acusadas pelo governo de "improdutivas", sendo permanentemente impelidas a prestarem conta de sua "produtividade", no âmbito do ensino, da pesquisa e da extensão. Para tal, desenvolvem-se mecanismos de avaliação da "produtividade" docente, departamental e institucional, nos níveis da graduação e da pós-graduação; tenta-se inserir as universidades na lógica do capital, vinculando-as ao setor produtivo, já que o Estado se desobriga cada vez mais do financiamento da pesquisa nestas instituições; procura-se transformar as universidades em agências prestadoras de serviços para a sociedade de mercado; privatiza-se o público, via pesquisas encomendadas por empresas, cursos "autofinanciáveis" que cobram mensalidades dos alunos, projetos de extensão realizados meramente com fins lucrativos, dentre outros., (Paula, 2002, p. 15-16).
\end{abstract}

Esta configuração influenciou diretamente a universidade pública a entrar em uma crise institucional, conforme Santos e Almeida Filho (2008); se esta existia antes, aprofundou-se. Essa crise institucional da universidade, na grande maioria dos países, foi provocada ou induzida pela perda de prioridade enquanto bem público nas políticas governamentais e pela consequente secagem financeira e descapitalização das universidades públicas. De todo modo, tratada como um fenômeno estrutural, o fato da crise institucional ter sofrido influência da crise financeira não significa que as suas causas se reduzam a esta.

De modo a superar a crise institucional, Santos e Almeida Filho apontam a necessidade de uma reforma da universidade pública que proponha uma transformação profunda e completa; isso implica rever e atualizar a arquitetura acadêmica, a estrutura organizacional, entre outros fatores. Assim, essa urgência por uma reforma da universidade pública configura também a renovação de sua proposta formativa, uma vez que a efetividade da educação superior não cessa no ensino de habilidades para a execução de uma determinada atividade profissional, mas se localiza no desenvolvimento da autonomia dos sujeitos para um entendimento profundo do sentido do fazer humano e uma interferência comprometida 
com a coletividade. Ou seja, qualquer tentativa de reforma na universidade precisa sempre ratificá-la como espaço de reflexão e exercício de valores e direitos sociais, dissipando, assim, a possibilidade de que o desenvolvimento da ciência e da tecnologia se converta em conformismo científico ou em assepsia miserável.

Por isso, o processo de transnacionalização da educação superior, em que pesem as fortes pressões para incluí-la nos acordos multilaterais da Organização Mundial do Comércio (OMC), justifica-se, em última instância, como medida para promover a qualificação das instituições mediante a inserção de sua produção no cenário mundial. Essa publicização do conhecimento, além de marcar o campo científico com as cores da cultura local, reflete diretamente nos processos de democratização da universidade, pois abre caminho para que grupos até então segregados se sintam motivados a contribuir na produção e na organização das aprendizagens do campo científico.

Neste sentido, a maré mercantilista perdeu significativa força na educação superior com o fim do Governo FHC. Embora a orientação dos ditames de organismos internacionais ainda persistisse, a compreensão da universidade pública por novas perspectivas no Governo Lula fez crescer expressivamente o número de vagas nas instituições públicas e privadas do País, isto porque a partir de 2003, já no Governo Lula, a universidade pública, de modo especial, passou por um novo projeto de expansão e de reforma que a sensibilizou para os grandes impasses e dilemas a serem superados pelo Brasil nas próximas décadas. Para isso, o Ministério da Educação (MEC) estabeleceu metas para a expansão da universidade pública por meio do programa Expansão das Universidades Federais: o Sonho se Torna Realidade, cujo objetivo geral se refere a "expandir o sistema federal de ensino superior, com vistas a ampliar o acesso à Universidade, promover a inclusão social e reduzir as desigualdades regionais" (Brasil. MEC, 2003, p. VI). Uma das mais importantes metas do programa diz respeito a chegar em 2008 com um ingresso anual de mais de 30.000 novos estudantes nos diversos cursos de graduação das Instituições Federais de Ensino Superior (Ifes). O compromisso de governo assumido foi o de garantir o acesso de jovens entre 20 e 24 anos de idade à universidade, visto que esse contingente, na época, somava uma população de menos de $8 \%$ nos bancos universitários.

De acordo com Santos e Almeida Filho (2008), a reforma da universidade pública brasileira implica aprofundar a sua reestruturação visando torná-la instrumento de emancipação de sujeitos e promotora de equidade e criando condições para a construção de um projeto viável de nação. É preciso lembrar aqui que, depois da primeira expansão resultante da reforma universitária de 1968, o crescimento do sistema federal de educação superior no final dos anos de 1990 foi iniciativa das próprias universidades públicas. Nesse momento, "a universidade abria cursos novos ou ampliava a oferta de vagas em cursos existentes sem contar com docentes, instalações, recursos financeiros; só depois se buscava criar as condições mínimas para tanto" (Santos, Almeida Filho, 2008, 
p. 190) - a esse tipo de crescimento, Santos e Almeida Filho chamam de "autonomia-sem-apoio". A segunda expansão - que está no foco de nossa atenção - ocorreu no primeiro Governo Lula e carregou a marca da interiorização da universidade brasileira, de forma a atender demandas históricas de lideranças político-partidárias. Nesta segunda etapa, as iniciativas eram tomadas pelo governo federal com pouco diálogo com as Ifes e precário reconhecimento de sua autonomia. Por esse motivo, Santos e Almeida Filho (2008, p. 191) consideram tratar-se de um crescimento do tipo "apoio-sem-autonomia".

A estratégia predominante baseava-se na implantação de cursos simultaneamente à contratação de docentes e realização dos investimentos necessários. Nessa fase, o financiamento era realizado durante a expansão de atividades da universidade. Os resultados dessa ampliação compreendem iniciativas patrimoniais ou institucionais, com 48 novos campi ou extensões, além de 10 universidades instituídas. (Santos, Almeida Filho, 2008, p. 191)

Contudo, a expansão foi mais além, atingindo também a esfera privada. Como lembram Michelotto, Coelho e Zainko (2006), tanto em função de demandas históricas quanto de novas, a ampliação do acesso também ocorreu por meio de concessão de bolsas para cursos de instituições privadas - trata-se do Programa Universidade para Todos (ProUni), criado em 2004 e institucionalizado pela Lei n ${ }^{\circ}$ 11.906/05 (Brasil, 2005). O ProUni, entretanto, tem sido alvo de críticas de diversos autores, pois, em sua concepção, permeia a ideia de que basta o acesso do aluno à educação superior para configurar sua democratização, desconsiderando a necessidade de construção de mecanismos para garantir a permanência desse estudante na instituição. Ante a impossibilidade de a população arcar diretamente com os custos da educação superior privada, o aumento da oferta de vagas não coincidiu com o incremento de matrículas, conforme dados do Inep (Brasil. Inep, 2007).

Uma reforma na universidade pública, considerando sua realidade jurídica, passa necessariamente por modificações nas políticas públicas, de forma a melhor explicitar o papel do Estado e dos governos no que se refere ao acesso dos estudantes à educação superior e à sustentabilidade pedagógica e estrutural do sistema universitário. No Brasil, historicamente, o setor privado se fortaleceu na promoção do ensino, em que pese o Estado, paulatinamente, ter diminuído sua atuação no âmbito da educação institucionalizada e, mais que isso, ter atuado frequentemente na esfera educacional por meio da iniciativa privada. Como Michelotto, Coelho e Zainko (2006) pontuam, existem discussões importantes a serem feitas sobre qualidade, relação entre formação universal e profissional e demandas da sociedade contemporânea, além do questionamento sobre a pertinência da redução da ociosidade nas instituições privadas mediante a destinação de vagas pelo ProUni.

Na mesma medida em que a reforma universitária ainda suscita debates e encaminhamentos para trâmite nas instâncias reguladoras, 
o Governo Lula empenhou-se na efetivação do projeto expansionista da universidade inaugurando um terceiro momento de expansão, o Programa de Apoio a Planos de Reestruturação e Expansão das Universidades Federais (Reuni), que surge no cenário brasileiro pelo Decreto ${ }^{\circ}$ 6.096, de 24 de abril de 2007, com investimento previsto de sete bilhões de reais até 2012, tendo o objetivo de criar condições para a ampliação do acesso e permanência na educação superior mediante a reestruturação física e incremento de recursos humanos e financeiros (Brasil, 2007). Toda instituição universitária que desejasse aderir ao Reuni deveria antes passar pelo crivo de suas próprias instâncias, o que significa, em certa perspectiva, uma relativa autonomia em relação ao programa. Para Santos e Almeida Filho (2008, p. 191), este modelo de desenvolvimento caracteriza-se como "apoio-com-autonomia":

\begin{abstract}
Agora temos um modelo induzido de crescimento das instituições públicas de educação superior que, por um lado, respeita a autonomia universitária, acolhendo propostas específicas, elaboradas por cada uma das instituições participantes do programa. Por outro lado, pela primeira vez, os investimentos em obras e instalações, a aplicação de recursos de custeio, a modelagem pedagógica, a contratação dos quadros docentes e de servidores, faz-se antes da expansão de atividades e de vagas.
\end{abstract}

O Reuni é um programa muito recente e com pontos sendo ainda discutidos por diversas comunidades acadêmicas, muito embora nenhuma instituição tenha se negado a participar do projeto, implementado mediante a aceitação dos conselhos máximos de cada universidade. Para Santos e Almeida Filho (2008, p. 191), o programa pode representar eficiência institucional e qualificação pedagógica, já que auxilia na redução de uma histórica dívida da educação superior com a sociedade. De qualquer modo, considerando-se que seja um programa de apoio à reestruturação e expansão muito recente, ainda carece de discussões para qualificar a construção de uma opinião pública crítica. A adesão de todas as Ifes em um curto espaço de tempo fez-se diante de discussões e críticas institucionais de modo superficial, limitando a responsabilidade das instâncias democráticas, assim como as possibilidades de efetivação das propostas de cada universidade. Cabe salientar ainda os riscos que o Reuni oferece para a dinâmica orçamentária das instituições, uma vez que "introduz no sistema federal de educação superior um modelo de gestão semelhante aos que regulam o repasse de recursos públicos do Sistema Único de Saúde" (Santos, Almeida Filho, 2008, p. 191). Esta configuração implica um plano de gestão a curto e médio prazo, imputando à universidade uma avaliação contínua em função da pertinência de seus resultados em ensino e pesquisa, bem como de seu impacto no desenvolvimento socioeconômico da região.

Enfim, do mesmo modo que no contemporâneo já não é mais possível argumentar em favor de uma "ideia de universidade" descolada das demandas sociais e avessa aos mecanismos de planejamento e avaliação, também se tornam uma temeridade as tentativas de apreender 
os processos educacionais por critérios exclusivamente quantitativos e racionalistas, isto porque qualquer tentativa externa de interferir na estrutura universitária carrega a tendência de sistematizar as ações de aprendizagem, pedagogizando-as no sentido de simplificar suas etapas, o que, por consequência, rompe com os elos entre a ciência e a vida, qualidade e desenvolvimento sustentável.

\section{Expansão universitária: o caso Cesnors}

Na tentativa de compreender criticamente o programa de expansão da universidade brasileira na última década, trazemos para o debate o contexto de criação do Centro de Educação Superior Norte (Cesnors), cujos campi se localizam nos municípios de Frederico Westphalen e de Palmeira das Missões. Ambos no Estado do Rio Grande do Sul, ficam a uma distância aproximada de $320 \mathrm{~km}$ de sua unidade sede, a Universidade Federal de Santa Maria (UFSM), que o criou em 20 de julho de 2005 pelo Parecer $n^{\circ} 031 / 05$. As atividades acadêmicas propriamente ditas tiveram início em 16 de outubro de 2006 e, atualmente, são uma referência de acesso à educação superior no norte do Estado. Dessa forma, a presente análise configura uma oportunidade para acompanhar a situação atual da universidade pública no interior do País, fornecendo elementos para uma avaliação crítica dos impactos sociais que sua interiorização produz numa região específica.

O Cesnors apresenta algumas peculiaridades organizacionais que vão além da estruturação em uma região distante da unidade sede. Não se trata de um centro especializado em uma área do conhecimento - o que é relativamente comum à realidade das universidades federais -, pois oferece cursos de graduação em distintas áreas. No campus de Frederico Westphalen, além dos cursos de Engenharia Florestal e Agronomia, há o curso em Ciências da Comunicação - habilitação em jornalismo. Ainda nesse campus, no segundo semestre de 2009, com o Reuni, foram implementados os cursos de Relações Públicas (multimídia) e Engenharia Ambiental. Já no campus de Palmeira das Missões, enquanto se consolidava o curso de Enfermagem, implementaram-se os de Administração (diurno e noturno) e Zootecnia, e, no segundo semestre de 2009, por meio do Reuni, o curso de Nutrição e Ciências Biológicas (licenciatura).

Nesse estágio, apesar do sensível crescimento no número de vagas oferecidas (totalizando 1.295 alunos), é importante salientar que ainda se sentia um déficit de recursos humanos e materiais para efetivar o projeto de expansão da educação superior com qualidade, produzindo um impacto positivo no desenvolvimento social para a região, isto porque, por exemplo, houve uma redução no número de vagas dispostas para a docência nos cursos: dos 138 docentes previstos no projeto inicial de expansão, apenas 93 estavam em atividade, e o número total poderia chegar a 104 docentes. Quanto ao espaço físico, somente a partir de 2009 o Cesnors acomodou-se em suas instalações, embora ainda inacabadas, pois se aguardava o 
gradativo cumprimento do cronograma de seu projeto de criação e do programa de adesão ao Reuni.

$\mathrm{Na}$ tentativa de melhorar o atendimento aos alunos carentes do Cesnors, foi realizado um mapeamento das informações dadas pelos alunos à Comissão Permanente de Vestibular (Coperves) no momento do ingresso à universidade. O perfil dos acadêmicos aprovados nos dois primeiros vestibulares do Cesnors (de 2006 e de 2007) mostrou que a maioria dos estudantes (73\%) tinha entre 15 e 21 anos de idade, ou seja, estava dentro da faixa etária alvo do programa de expansão universitária do Governo Lula. Nessa fase, os estudantes estavam ainda dependentes financeiramente de seus pais, que precisavam arcar com os custos de transporte, moradia, alimentação e material didático. Além disso, os acadêmicos procedem de diversos municípios gaúchos e, também, de diferentes Estados, o que implica a necessidade de uma estrutura de moradia nos municípios onde estudam. Esses alunos, em grande parte (74\%), são provenientes de escolas públicas, o que pode ser um indicativo da falta de recursos para custear o ensino em instituições particulares, além da própria democratização da educação superior pública. No levantamento da Coperves, 40\% dos acadêmicos indicaram renda familiar mensal de até três salários mínimos. Perguntados sobre como pretendiam sustentar seu custo de vida durante a graduação, 38\% dos ingressantes responderam que seria com recursos familiares, embora constatadas as dificuldades para isso.

A partir do levantamento desses dados, delineou-se o perfil socioeconômico dos universitários ingressantes no Cesnors até 2007, o que subsidiou também a UFSM no planejamento de políticas de assistência estudantil, indo ao encontro das necessidades dos acadêmicos na medida das possibilidades orçamentárias da universidade. Certamente, o fato de os campi do Cesnors se localizarem fora das zonas urbanas dos municípios sede - além da própria distância da unidade central da UFSM -, associado à falta de condições estruturais e ao alto custo de vida nas localidades, dificultou a implementação de ações de assistência (refeições subsidiadas em restaurantes universitários, prédios para moradia estudantil, bolsas de incentivo à pesquisa, etc.). O que fez crescer ainda mais a distância entre as possibilidades oferecidas pela instituição e as demandas dos estudantes foram as expectativas pessoais e familiares com o ingresso na universidade. Toda a comunidade acadêmica buscava constantemente informações sobre os investimentos no Cesnors, visto que a UFSM, em sua unidade central, dispõe de uma boa estrutura (material e de gestão) de assistência estudantil. Entretanto, tendo o acesso à universidade pública como diretriz principal para a implementação desse programa de expansão, foram desconsideradas essas questões da ordem do imaginário social, muito embora o Projeto Acadêmico de Criação do Centro de Educação Superior Norte (UFSM, 2005) previsse a construção de restaurante universitário e moradia estudantil, entre outros benefícios.

Um estudo realizado pela própria universidade, documentado no Relatório para Implantação do Programa de Assistência Estudantil 
(UFSM, 2007), apontou para questões mais profundas a respeito dessa transformação promovida pela instalação dos campi nos dois municípios anteriormente citados. A estrutura universitária em si já representa um fator de fomento ao crescimento econômico regional, ampliando-se depois para outros aspectos sociais. Neste sentido, as atividades universitárias de ensino, pesquisa e extensão contribuem para o desenvolvimento regional não apenas através de ações diretas e pontuais, mas pelos processos de aprendizagem imanentes à investigação científica. Todavia, cabe aqui a ressalva de que não se trata de um tipo de autogestão das universidades, em que uma participação funcional na administração das instituições é o suficiente para manter sua sustentabilidade social. Longe desta perspectiva asséptica, a racionalidade social da universidade ampara-se no processo de retroalimentação da própria ciência, isto é, as problematizações sentidas no campo da prática são estudadas aos olhos do paradigma científico e retornam de forma reelaborada para a esfera das relações sociais. No entanto, ao localizarmos este círculo reflexivo diante das configurações plurais do contemporâneo para além do saber científico, sentimos a necessidade de marcar suas etapas com nuanças éticas e estéticas, de modo que o conhecimento da universidade não seja hipostasiado interna ou externamente à acadêmica. Constantemente, questões sobre o trato da diversidade, da transculturalidade ou da tolerância invadem a esfera pública do debate, pondo à prova a suficiência do conhecimento científico na organização das práticas político-culturais - isso justifica a postura prudente que devemos alimentar acerca das expectativas sociais depositadas na universidade. Apesar de sua posição privilegiada de interferir nos caminhos do desenvolvimento da sociedade, nenhum segmento pode ser responsabilizado sozinho pelas transformações que se fazem necessárias (Goergen, 2008, p. 811).

\section{Considerações finais}

Compreender a abrangência da educação superior vai mais além do que somente entendê-la no escopo de uma atividade econômica; é uma função essencial, de interesse público, mas que não deve ser entendida como ação exclusiva do Estado, do mesmo modo que este, por não ter exclusividade no campo educacional, pode deixar de fazê-lo. Além disso, o Estado tem uma função irrenunciável na constituição e regulação de um sistema nacional de educação superior, que se configura no apoio e fomento às pesquisas, articulando de modo qualificado a instância local e global no sentido do desenvolvimento social sustentável e protegido dos processos de mercantilização.

Enfim, ao atual programa de expansão da universidade brasileira, que teve o acesso como princípio norteador, cabe agora tomar iniciativas mais efetivas para enraizar a qualidade da educação superior nos processos político-culturais do mundo vivido. Até o momento, os instrumentos avaliativos da qualidade da educação superior deram conta, em certa 
medida, dos aspectos operacionais e da performatividade da relação pedagógica, o que corrobora diretamente os interesses economicistas do sistema produtivo. Diferente disso, uma racionalidade educativa pautada na formação do cidadão crítico e nos valores humanos e culturais mais caros não sublinha a adaptação às demandas imediatas, mas reforça a necessidade da totalidade do desenvolvimento ético, cultural, ecológico e econômico.

O Cesnors aderiu ao Reuni na tentativa de corrigir falhas de seu projeto inicial de expansão, visto que a oferta de mais cursos e a abertura de mais vagas seria uma oportunidade de reaver recursos materiais e humanos previstos inicialmente e cortados depois - para implementar a unidade universitária com certa qualidade. De toda forma, a criação do Cesnors indica que o início de um processo de profunda democratização da educação superior já começou, embora não seja nada fácil uma reestruturação da universidade pública sob o critério da sustentabilidade ético-cultural.

Do ponto de vista da formação da opinião pública sobre o significado da expansão da universidade e da democratização do seu acesso, ainda persiste um diálogo distorcido que alimenta excessivas expectativas acerca do poder de transformação do saber científico e entende o espaço universitário exclusivamente por sua função de formar profissionais para o sistema produtivo. Embora de forma partilhada, entendemos que a universidade pode aproveitar seu espaço privilegiado na esfera pública para debater a ideia de universidade possível no contemporâneo, publicizando os processos de aprendizagem típicos à investigação científica e abrindo-se para uma escuta sincera - sem fins objetivistas - da diversidade cultural hoje vivida. É nesta perspectiva que apostamos na construção de uma consciência corporativa, firmando assim os laços entre universidade e sociedade e enraizando as identificações produzidas nesta relação nos processos formativos dos sujeitos cidadãos.

\section{Referências bibliográficas}

BRASIL. Decreto no 6.096, de 24 de abril de 2007. Institui o Programa de Apoio a Planos de Reestruturação e Expansão das Universidades Federais - Reuni. Brasília, 24 abr. 2007. Disponível em: < http://www. planalto.gov.br/ccivil_03/_Ato2007-2010/2007/Decreto/D6096.htm>. Acesso em: 30 out. 2010 .

BRASIL. Instituto Nacional de Estudos e Pesquisas Educacionais Anísio Teixeira (Inep). Sinopses estatísticas. Disponível em: < http://www.inep. gov.br/superior/censosuperior/sinopse/default.asp >. Acesso em: 10 ago. 2007.

BRASIL. Ministério da Educação. Expansão das universidades federais: o sonho se torna realidade Período de 2003 a 2006. Brasília: MEC, 2003. 
BRASIL. Ministério da Educação. Reforma universitária. [online]. Disponível em: < http://mecsrv04. mec.gov.br/reforma/default.asp>. Acesso em: 10 abr.2009.

CHAUÍ, Marilena de Souza. Entrevista ao Programa Roda Viva - TV Cultura. 3 maio 1999. Disponível em: < http://www.rodaviva.fapesp.br/ materia/61/entrevistados/\%20marilena_chaui_1999.htm>. Acesso em: 25 mar. 2011.

Escritos sobre a universidade. São Paulo: Ed. Unesp, 2001.

GERHARDT, Volker. A ideia de Humboldt: sobre a atualidade do programa de Wilhelm Von Humboldt. In: ROHDEN, Valério (Org.). Ideias de universidade. Canoas: Ed. Ulbra, 2002. p. 13-34. (Série Filosofia, 2).

GOERGEN, Pedro. Educação superior: entre formação e performance. Avaliação, Campinas; Sorocaba, v. 13, n. 3, p. 809-815, nov. 2008.

HABERMAS, Jürgen. A ideia da universidade: processos de aprendizagem. Revista Brasileira de Estudos Pedagógicos, Brasília, v. 74, n. 176, p. 111-130, jan./abr. 1993.

MICHELOTTO, Regina Maria; COELHO, Rúbia Helena; ZAINKO, Maria Amélia Sabbag. A política de expansão da educação superior e a proposta de reforma universitária do Governo Lula. Revista Educar, Curitiba, n. 28, p. 179-198, 2006.

PAULA, Maria de Fátima Costa. A influência das concepções alemã e francesa sobre a Universidade de São Paulo e a Universidade do Rio de Janeiro quando de suas fundações. In: REUNIÃO ANUAL DA ASSOCIAÇÃO NACIONAL DE PÓS-GRADUAÇÃO EM EDUCAÇÃO, 25., 2002. Caxambu/MG. Anais... Caxambu/MG, 2002. 1 CD-ROM.

SANTOS, Boaventura de Sousa; ALMEIDA FILHO, Naomar de. A universidade no século XXI: para uma universidade nova. Coimbra: 2008. Disponível em: < http://www.boaventuradesousasantos.pt/ media/A\%20Universidade\%20no\%20Seculo\%20XXI.pdf>. Acesso em: 20 abr. 2009.

TRIGUEIRO, Michelangelo Giotto Santoro. Universidades públicas: desafios e possibilidades no Brasil contemporâneo. Brasília: Ed. UnB, 1999.

UNIVERSIDADE FEDERAL DE SANTA MARIA. Projeto Acadêmico de Criação do Centro de Educação Superior Norte-RS/UFSM. Santa Maria, nov. 2005. 
UNIVERSIDADE FEDERAL DE SANTA MARIA. Centro de Educação

Superior Norte-RS. Relatório para Implantação do Programa de

Assistência Estudantil. Frederico Westphalen, 2007.

Jorge Paiva da Silva, especialista em Gestão Educacional pela Universidade Federal de Santa Maria (UFSM), é membro do Grupo de Pesquisa Inovação e Avaliação na Universidade, (Grupo Inovaval - CNPq/ UFRGS).

malejorge@hotmail.com

Maiane Liana Hatschbach Ourique, doutoranda do Programa de PósGraduação em Educação da Universidade Federal de Santa Maria (PPGE/ UFSM), é membro do Grupo de Pesquisa Formação Cultural, Hermenêutica e Educação (GPFORMA - CNPq/UFSM).

maianeho@yahoo.com.br

Recebido em 20 de abril de 2011.

Aprovado em 17 de janeiro de 2012. 